\title{
Parathyroid Cysts - An Unusual Cause for Primary Hyperparathyroidism
}

Shailesh Gohil, Vimal Venugopal, Sing Sim, Marie-France Kong, Miles Levy Leicester Royal Infirmary, Infirmary Square, Leicester, LE1 5WW, UK

\section{Patient 1}

- $500^{7}$ - Incidental finding of raised calcium

\begin{tabular}{|c|c|c|c|c|}
\hline & Calcium & Phosphate & PTH & Vit D \\
\hline & $3.52 \mathrm{mmol} / \mathrm{L}$ & $0.66 \mathrm{mmol} / \mathrm{L}$ & $99.5 \mathrm{pmol} / \mathrm{L}$ & $46 \mathrm{nmol} / \mathrm{L}$ \\
\hline Normal & $2.2-2.6$ & $0.8-1.5$ & $1.6-7.5$ & \\
\hline
\end{tabular}

- Ultrasound neck $-1.2 \times 1.5 \mathrm{~cm}$ left sided nodule and $3.3 \times 3.2 \times 1.7 \mathrm{~cm}$ right sided cystic mass

- Isotope MIBI negative

- Left nodule removed

- Histology - thyroid nodule and normal parathyroid gland

Recurrent severe hypercalcaemia with AKI

- Right sided lesion re-visited
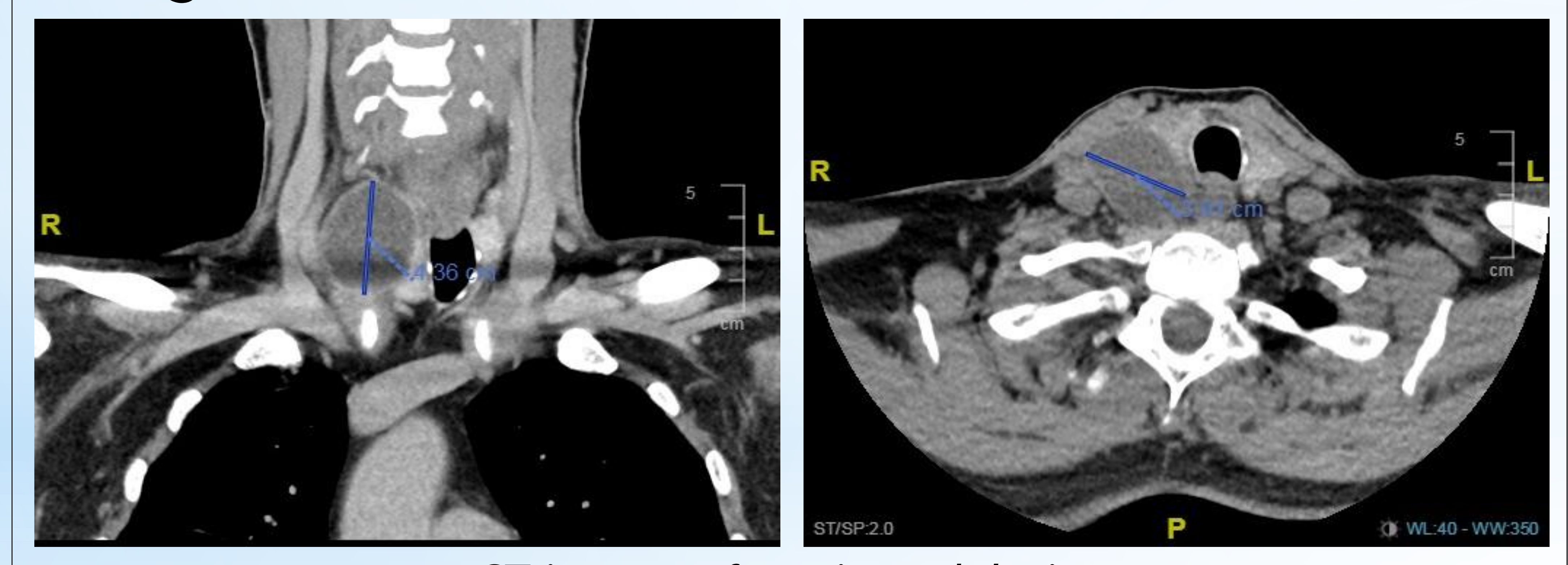

CT images of cystic neck lesion

- Cyst fluid aspirated and sent for PTH analysis

- $\mathrm{PTH}>200 \mathrm{pmol} / \mathrm{L}$

- Right sided lesion removed

- Histology - Parathyroid adenoma with cystic degeneration

- Hypercalcaemia resolved

\section{Patient 2}

- $73 \sigma^{7}$ - Incidental finding of raised calcium

\begin{tabular}{|c|c|c|c|c|}
\hline & Calcium & Phosphate & PTH & Vit D \\
\hline \multirow{2}{*}{ Normal } & $2.79 \mathrm{mmol} / \mathrm{L}$ & $0.50 \mathrm{mmol} / \mathrm{L}$ & $30.0 \mathrm{pmol} / \mathrm{L}$ & $28 \mathrm{nmol} / \mathrm{L}$ \\
\hline & $2.2-2.6$ & $0.8-1.5$ & $1.6-7.5$ &
\end{tabular}

- Asymptomatic but serial rise on monitoring

- Ultrasound neck - 3.5x4.4cm right sided cyst

- Isotope MIBI scan normal

- DEXA normal
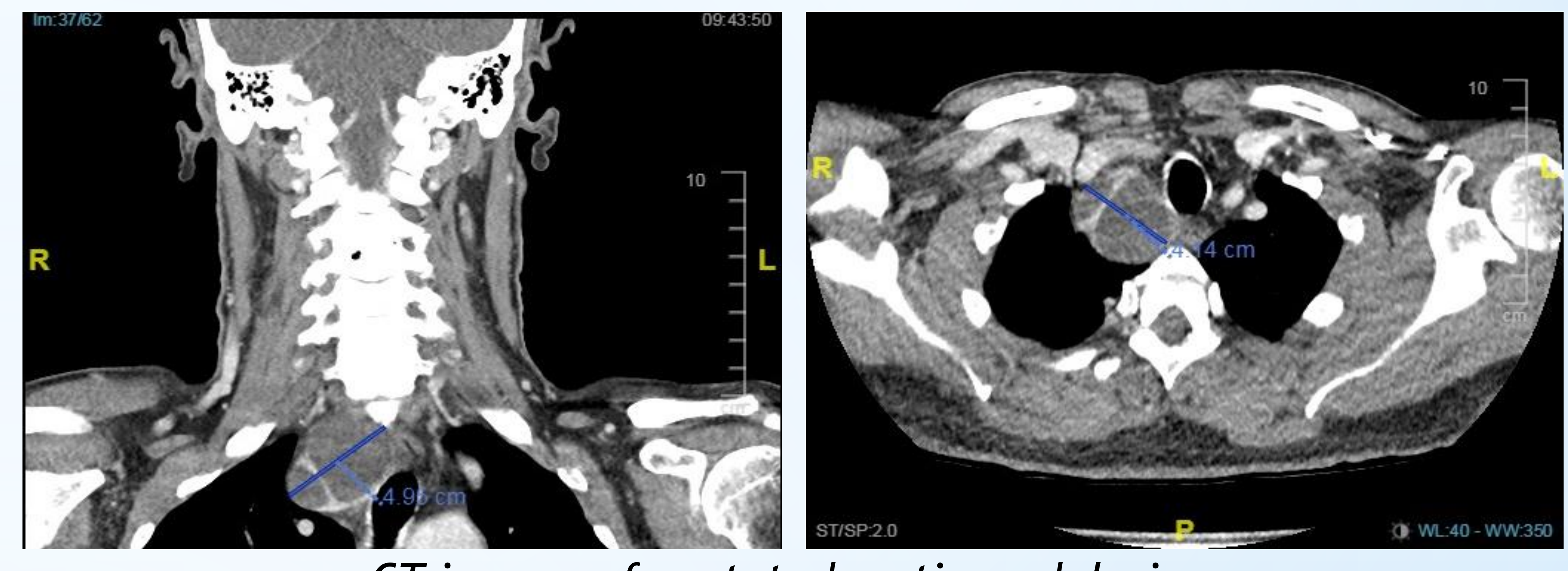

CT images of septated cystic neck lesion

- Cyst fluid aspirated and sent for PTH analysis

- $\mathrm{PTH}>200 \mathrm{pmol} / \mathrm{L}$

- Awaiting surgical removal

\section{Key Learning Point}

If your patient has primary hyperparathyroidism with a cystic neck mass, consider aspirating it and send fluid for PTH analysis.

\section{Parathyroid Cysts}

First described in 1880

Around 300 cases reported

Rare: $0.5-1 \%$ of parathyroid lesions are cysts. Of these, only $10-15 \%$ functional

Can present with incidental neck lump or primary hyperparathyroidism

Only 29\% positively identified on isotope MIBI scan - not sensitive for cysts

Key to diagnosis is markedly raised PTH in aspirated fluid

Treatments for non-functional cyst include aspiration or ethanol ablation

Definitive treatment for functional cyst is surgical excision - indication same as hyperparathyroidism Malignant transformation rare

References

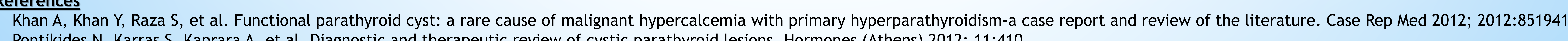
Pontikides N, Karras S, Kaprara A, et al. Diagnostic and therapeutic review of cystic parathyroid lesions. Hormones (Athens) $2012 ; 11: 410$.

Cappelli C, Rotondi M, Pirola I, et al. Prevalence of parathyroid cysts by neck ultrasound scan in unselected patients. J Endocrinol Invest 2009; 32:357. 